\title{
Failures of US bridge rocker bearings
}

Julie Mark Cohen PhD, PE, SECB

Consulting Structural and Forensic Engineer, Latham, NY, USA

(corresponding author: jmcohen@jmcohenpe.com)

\author{
Volker Wetzk Dr-Ing \\ Structural Engineer and Scientific Assistant, Brandenburg University of \\ Technology Cottbus-Senftenberg, Cottbus, Germany
}

Bridge bearings made of iron or steel, first used in early railroad bridges about 150 years ago, are relatively small structural components that support the loads of bridge superstructures. Fixed bearings directly transfer forces from a bridges superstructure to its substructure. Movable bearings, such as sliding bearing plates, rollers and rockers, accommodate the thermal expansion of the superstructure without transferring it to the substructure. Rocker bearings tilt to accommodate thermal movement, theoretically without imposing stresses on the substructure. This paper concerns rocker bearings which are non-redundant components and have two states: stable and toppled over. When these bearings topple over, no alternate load paths exist, which results in a failed superstructure. As such, rocker bearings are critical bridge components. An overview is given of the history of use and failures of rocker bearings from nineteenth-century railroad bridges to US highway bridges with tall and slender rocker bearings that date from the late 1950s.

\section{Rocker bearings use and first signs of danger}

The use of bridge rocker bearings dates back to the early use of iron/steel for bridge structures. In the US, an early example was found in the 1857-1859 construction of the Green River Bridge in Kentucky as part of the Louisville-Nashville Railway (Figure 1). With its simple design, this type of movable bearing started a multicentury usage in US bridge construction.

However, rocker bearings have not performed as anticipated. They have repeatedly failed since their introduction some 150 years ago. With respect to late nineteenth-century railroad bridges, Morison (1893: p. 21) stated, 'Among the special details of bridge construction one of the most important is the provision for changes of length due to temperature, and while this is a provision which is nearly always made, it is, unfortunately, one of the details on which least care is bestowed. For many years, I have observed the defects of the expansion bearings of bridges as generally constructed, and it has seemed to me that the time has come when the attention of engineers should be called to these defects and to the arrangements which, I believe, will obviate the worst existing difficulties'. Morison (1893: p. 21) continued, 'Rockers are an attractive design, and have some advantages over other plans. The rocker is in fact nothing but a section of a wheel, the weight being carried on the axle and the wheel rolling on its circumference. There are two objections to a rocker bearing: the great weight that must be carried on the axle and the friction on this axle. The friction causes more or less sliding motion; the result of this sliding motion is to work the bearing gradually toward one edge of the section, so that at length the rocker falls over. Rockers were used considerably 25 years ago; they are now almost abandoned'. Morison's conclusion was incorrect regarding the abandonment of rocker bearings.

\section{Rockers become tall and slender}

In the 1920s, rocker bearings were introduced into highway bridges. After World War II, rocker bearings were also used for bridges with longer span lengths. To accommodate longitudinal thermal expansion and contraction of those spans, taller rocker bearings with adequately sized rocker plates were required.

The rocker bearings of interest here are shown in Figure 2. Those in Figure 2(a) can be described as a reduced single roller. Shown in both Figures 2(b) and 2(c) are sections of a wheel hinged at the top, but in different manners (pin or pintle). The type in Figure 2(b) is shown in Figure 1.

Apparently, the behaviour of tall slender rocker bearings has not been well understood for a long time. This is shown in the report and discussion of the 22 May 1952 collapse of a 29·3-m (96-ft) span of the new Sullivan Square Overpass in the Charleston section of Boston, Massachusetts (Anon, 1952). Initially blame was placed on improper installation of rocker bearings, which led to their subsequent excessive tilting. Specifically, investigators concluded that the rocker bearings had been installed with 'a relatively large angle with the vertical, to allow for anticipated temperature changes and pavement loads. This created a great horizontal thrust which resulted in the collapse of the rockers and the beams resting thereon'.

In a reader comment published in Engineering News-Record (Young, 1952: p. 10), the toppled rocker bearings of the Sullivan Square Overpass were described as being 'commonly designed with the center of the rocker surface at the center of the pin', and, as such, 'the rocker is merely a segment of a wheel, and its reaction (neglecting friction) is normal to the bearing plate'. Another reader comment published in Engineering News-Record (Boynton, 1952: p. 10) noted that 'this type of rocker should 


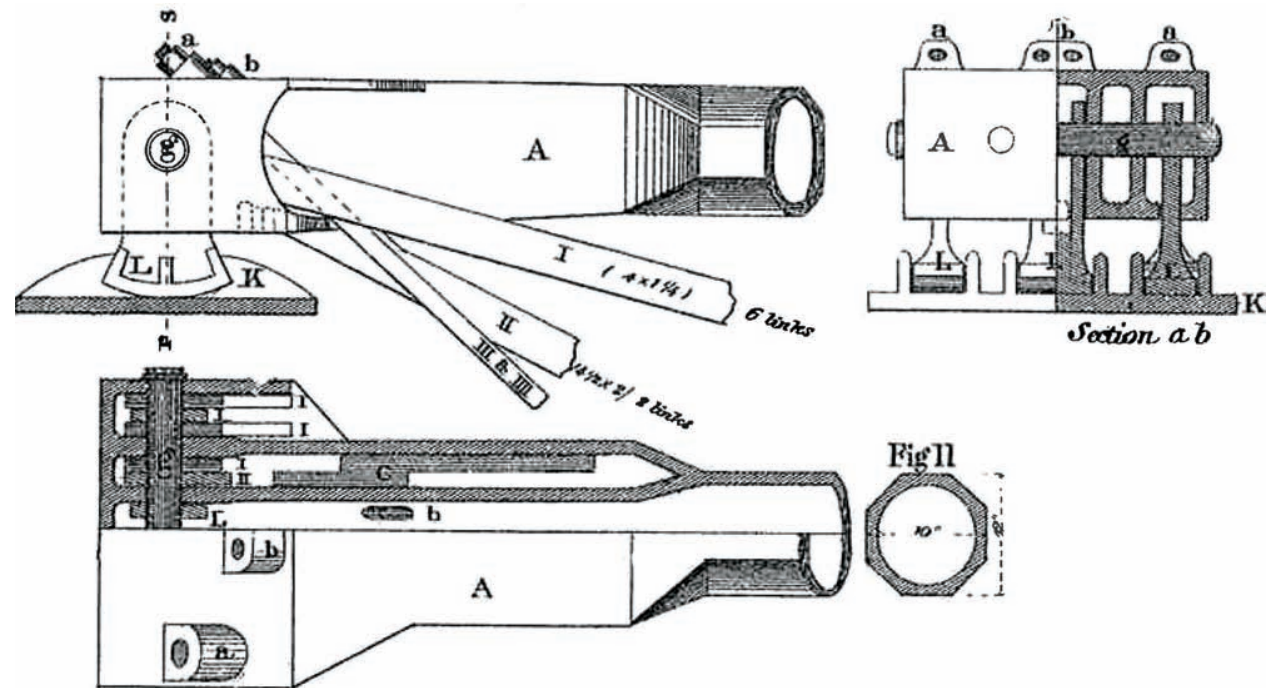

Figure 1. Bearing of the Green River Bridge as part of the Louisville-Nashville Railway (Cooper, 1889, plate 15)

generally be avoided; it may be properly used when the structure carried and the support against which it reacts are sufficiently rigid to effectively overcome the thrusts produced'. Yet the conclusion states, 'a flexible column and a rocker of the type used are each, individually, sound structural units. To use them in combination, without extreme precautions, only invites disaster'. Sixty years after the advice of Morison (1893), this warning remained unheard.

\section{Design criteria by US and state government agencies}

By the mid-1960s, new federal and state agencies were created. In late 1966, the US Department of Transportation was established. Subsequently, from 1967 through the early 1970s, departments of transportation (DOTs) for the states and those for the District of Columbia and Puerto Rico were established. For design requirements that were not developed in part or in total at the federal level such those as for rocker bearings, each US state developed its own criteria, which has resulted in a broad variety of rocker bearing designs.

The minimum heights of bearings were described by the National Cooperative Highway Research Program (NCHRP, 1977: p. 8):
'Bearings should be arranged with at least $152 \mathrm{~mm}$ (6 in.) clearance between the pier and the soffit of the beams. This clearance is a minimum to allow for cleaning or jacking when bearings must be repaired. When no clearance exists, temporary supports on which to place jacks must be brought up from the ground'. This clearance may also have been specified for ease of inspection and maintenance.

Taller rocker bearings were finally defined by the New York State Department of Transportation (NYSDOT, 2005a: p. 1) in a memorandum as follows: 'A high rocker bearing is generally taller than it is wide and, for these [inspection and monitoring] requirements to apply, at least $200 \mathrm{~mm}$ (8 in.) high'. NYSDOT (Christian, 2010) provided copies of as-built 1970 drawings for rocker bearings with clearances of $381 \mathrm{~mm}(15 \mathrm{in}$.) and $521 \mathrm{~mm}$ ( 20.5 in.) between the top of the concrete 'pad' on the pier and the underside of the girders. The overall-height-to-maximumwidth aspect ratios were on the order of 1.4 to 1.5 .

\section{Rocker bearing failures}

Apart from the Sullivan Square Overpass failure in 1952 mentioned earlier, highway rocker bearings did not acquire any

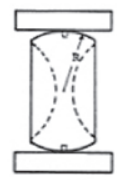

(a)

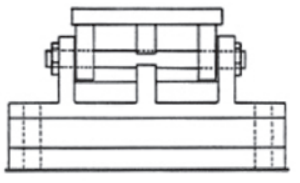

(b)

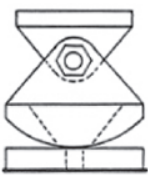

Figure 2. Rocker expansion shoes (Mazroi et al., 1982): (a) typical segmented rocker shoe; (b) typical pinned rocker shoe; (c) typical pintle rocker shoe (figure reprinted with permission of Prof. Emeritus Thomas M. Murray, Virginia Polytechnic Institute)

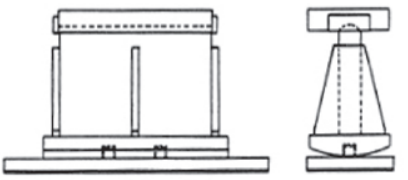

(c) 


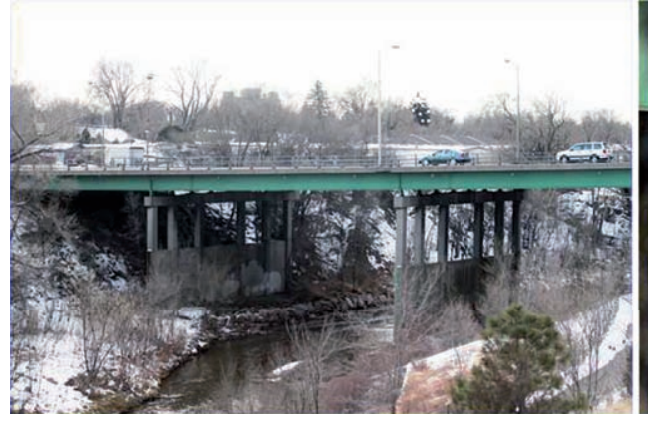

(a)

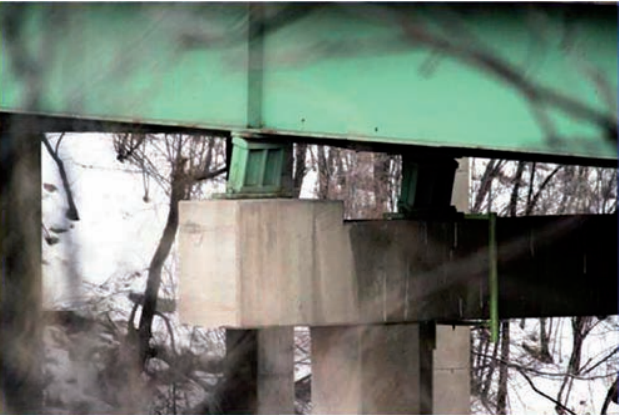

(b)

Figure 3. Fillmore Street Bridge, Colorado Springs, Colorado: (a) view showing the slender substructure; (b) extremely tilted rockers (photographs reprinted with permission of Bill Vogrin, author and photographer, and The Colorado Springs Gazette)

particular notoriety until recent decades when a number of somewhat taller, more slender rocker bearings became severely tilted (Figures 3 and 4) or toppled (Figure 5); other examples can be found in Cohen (2013)

\section{Lack of maintenance}

The bearings' 'long-term efficiency and success depend largely on the degree of maintenance they receive' (NCHRP, 1977: p. 4). The lack of maintenance of bearings, however, tends to be more the rule than an exception; thus, debris in bearings is often present, decreasing the ability of the bearings to accommodate thermal movement. As such, even 'movable' bearings transfer significant horizontal forces, frequently causing damage on the super- or substructure. Neglected maintenance is neither a problem of earlier times nor a specific problem of tall rocker bearings nor a problem of the US! Maintenance has always and everywhere been a crucial factor (Figure 6).

Also, in the case of rocker bearings, failures have been caused by accumulation of debris below the rockers. As noted by the
Pennsylvania Department of Transportation (PennDOT, 2008: p. IG 1.2.17), 'When debris encroaches beneath the rocker base plate during one season, the movement capacity of the bearing for alternate seasons is compromised, and the rocker will display an abnormal tilt proportional to the amount of debris trapped under the rocker. Over time, continued accumulation of debris and corrosion material incrementally increases the bearing tilt to unsafe angles. This phenomenon [is called a] ratcheting effect'. This extreme tilt generates vertical and horizontal force components. Since the bearing's rotation in the reverse direction is blocked by the debris, the horizontal force component may be sufficient to move the pier, giving place for additional debris. Over the years the repeating effect increases the tilt, possibly enough to topple the rocker (Figure 7).

Ratcheting may have been one of the motivating factors for several laboratory research projects, one of which was conducted by Mazroi et al. (1982). This experimental investigation was performed to determine the effective coefficient of friction of four classes of steel bridge bearings used by the Oklahoma Department

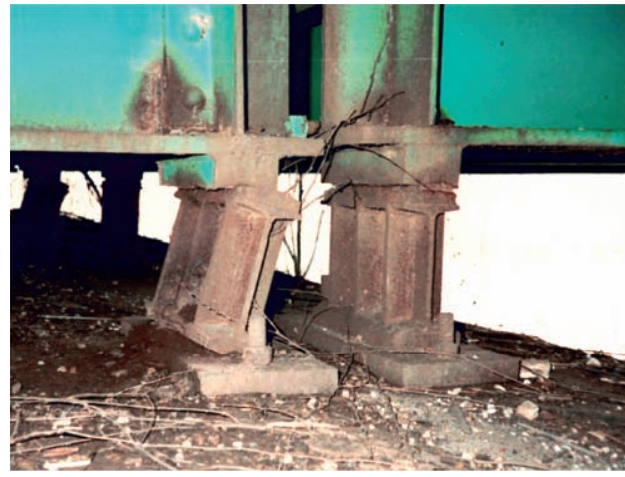

(a)

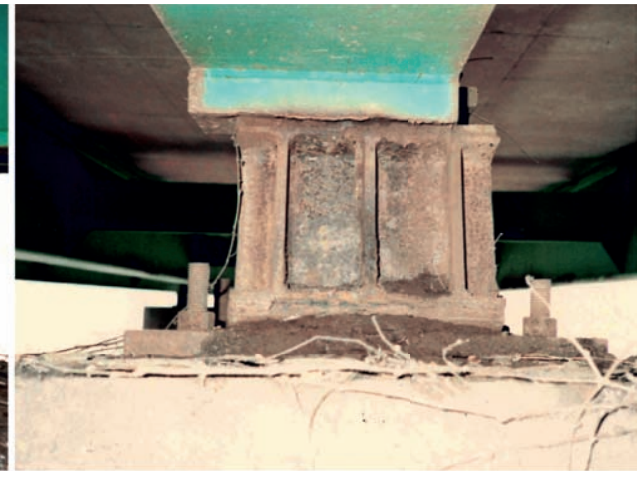

(b)
Figure 4. Bridge in south-eastern US: (a) extremely tilted rocker bearing; (b) tilted rocker bearing improperly located, possibly due to construction flaws and/or as a result of lateral translation of the superstructure (photographs reprinted with permission of anonymous) 


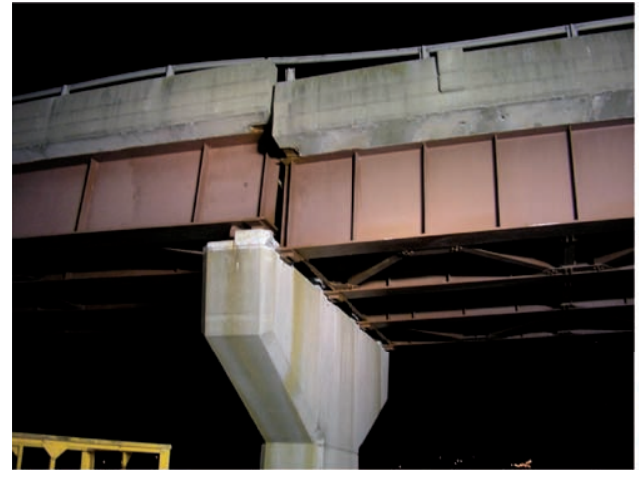

(a)

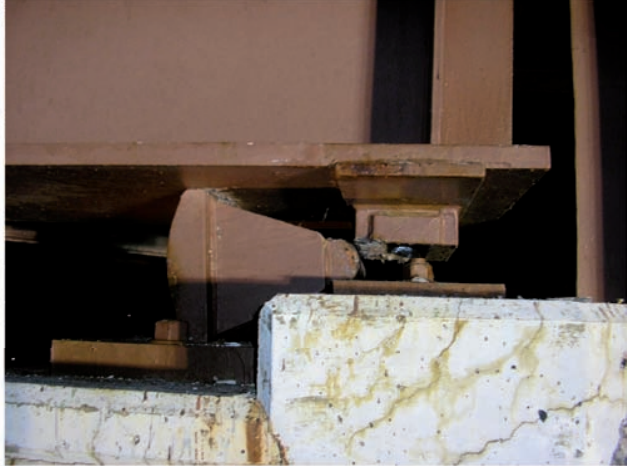

(b)

Figure 5. Interstate 787 elevated ramp, exit 3B north, Albany, New York: (a) dropped superstructure; (b) toppled over rockers (see Christian, 2010, and NYSDOT, 2005b, respectively) (photographs reprinted with permission of NYSDOT)

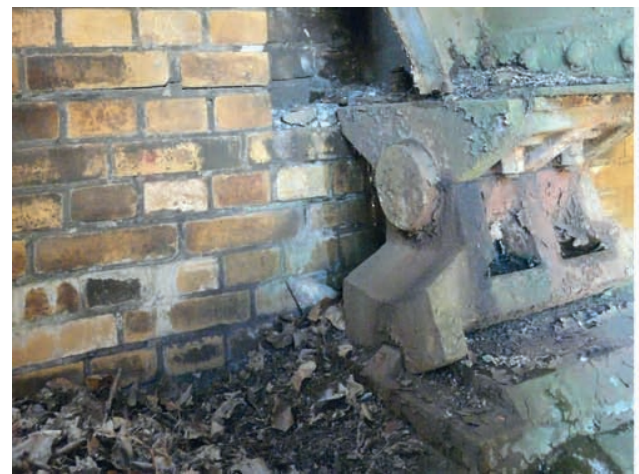

(a)

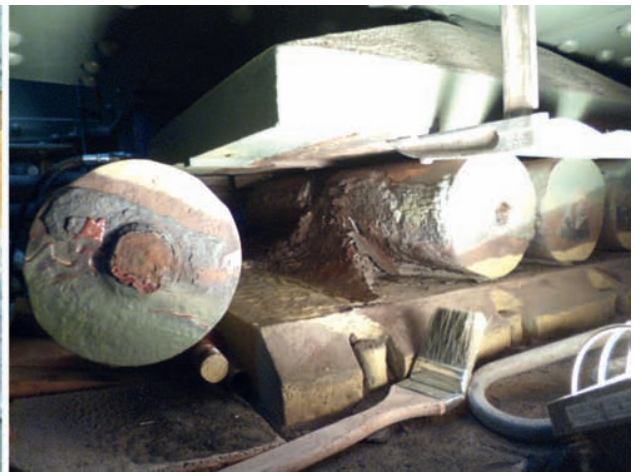

(b)
Figure 6. Examples of neglected bearing maintenance: (a) suburban railway bridge, Berlin-Rahnsdorf, Germany (photograph: Volker Wetzk); (b) bridge across the Lech River,
Augsburg, Germany, during repair work (photograph reprinted with permission of Other Montagen)
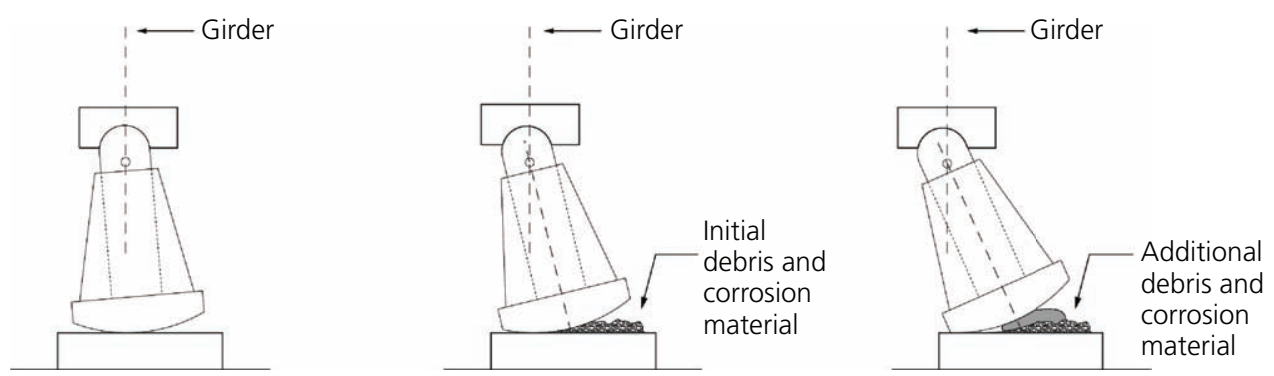

Figure 7. Ratcheting effect causing critical tilting of rocker shoes (reprinted with permission from PennDOT)

of Transportation. The researchers tested full-scale, as-built, rusted bearings with their debris under normal loads, with consideration of manufacturers' tolerances. Their results included the following: 'Tests with rusted bearing plates or with sand spread over the lower bearing plate showed significant increases in the effective coefficient of friction' (Mazroi et al., 1982: p. 71). The increase in the coefficient of friction adversely affected the ease at which the rocker bearings rotated. 


\section{Inspection routine}

It may be concluded that a major contributing factor for the bearings' failure has been insufficient maintenance. Even if older bridge maintenance manuals did not specifically include requirements to check for the presence of debris, each bridge inspector should notice any significant debris and ask the bridge owner to clean the bearings. It is more likely that this cleaning was inadequately performed or not performed; one reason may have been insufficient budgets to pay for maintenance. However, the current inspection manual of New York State explicitly requires the check 'of corrosion (including pack rust) or any debris that could inhibit proper function and documentation of section loss to any portion of the bearing assembly including anchor bolts' (NYSDOT, 2014a: pp. 4C-19).

The NYSDOT condition rating scale for bridges ranges from 1 to 7 , with 7 being in new condition. NYSDOT defines a deficient bridge as one with a state condition rating less than $5 \cdot 0$, requiring corrective actions to restore the bridge to its non-deficient condition. It does not mean that the bridge is unsafe. PennDOT (2010) stated that a 'critical deficiency' will 'increase structural vulnerability'. A critical deficiency exists if any rocker bearing exceeds the acceptable limit of tilt, which these documents define as 'the rocker is bearing on the outer one-quarter of its width at a pier with two lines of expansion bearings'. New York State (NYSDOT, 2014b) uses the same 'one-quarter' acceptable limit criterion.

For each rocker bearing, a rating of 2 out of 7 indicates a potential problem. However, when this 2 rating is entered as one of hundreds of ratings of all inspected bridge components, even if it is somehow weighted to increase its contribution to the overall rating number, its importance as a critical component seems to be overlooked. That is, it seems that during overall bridge assessment, the critical nature of rocker bearings has not been adequately taken into account.

\section{Bridge rocker bearings: present-day practice}

According to the Federal Highway Administration (FHWA, 2015: p. 8), 'Mechanical bearings such as metal bolsters, metal rockers, and roller bearing assemblies are viewed by many as an outdated system with high initial costs and costly long term maintenance requirements'. FHWA (2015: p. 4) continued, 'The metal-to-metal contact typically results in corrosion and eventual "freezing" of the bearing components. Lubricants have been used to mitigate corrosion, but trap debris, which in turn holds moisture and promotes corrosion. Mechanical bearings should not be specified for new designs unless special circumstances exist. For example, this bearing type might be used in bridge widening projects where existing bearing styles must be matched'.

For states with moderate and high levels of seismicity, as of 1980 state DOTs prohibited the use of rocker bearings for new bridges. The main reason was stated by FHWA (2006: p. 115) and supported by NYSDOT (2006a, 2006b): 'The rocker bearing is the most seismically vulnerable of all bridge bearings because it usually has a high aspect ratio, is difficult to restrain, and can become unstable and overturn after limited movement. Fixed bearings with high aspect ratios can also be very vulnerable to earthquakes'. FHWA (2006: p. 115) also pointed out that 'Since skew has a major effect on the performance of bridge bearings, rocker bearings may overturn at heavily skewed supports during only moderate seismic shaking. In such cases, it is necessary to consider the potential for collapse of the span, which will depend to a large extent on the geometry of the bearing seat. Settlement and vertical misalignment of a span due to an overturned bearing may be a minor problem, resulting in only a temporary loss of access that can be restored, in many cases, by backfilling with asphalt or other similar material. The potential for total loss of support should be the primary criteria when rating the vulnerability of the bearings'.

NYSDOT (2006b: p. 12-1) strengthened its argument by stating, 'Steel rocker bearings do not allow for transverse movement. These bearings were widely used in New York through the 1970s. Steel rocker bearings have fallen out of favor due to concern regarding their performance in extreme site conditions (e.g., steep grade) or during a seismic event. The relatively tall bearings could tip over and cause the superstructure to drop a considerable distance or, in the worst-case scenario, to fall off of the bridge seat. Steel rocker bearings also require periodic maintenance to ensure their performance. This bearing type is no longer used on new bridges'. However, rocker bearings are still used in new design in states with low seismicity, such as Kansas and Wisconsin. The FHWA (2012: p. 6) stated, 'Rockers, rollers, and sliding types are common expansion styles historically used and under certain circumstances can still be used today'.

Such circumstances, for example, are projects in which existing rocker bearing shapes/styles must be matched. For example Caltrans (1994: p. 2) stated, 'On [bridge] widenings, designers are cautioned against mismatching bearing types. It has been common practice to use elastomeric bearing pads, a yielding bearing, to widen structures supported on steel rocker bearings, an unyielding bearing. While this practice has worked satisfactorily on short to moderate length structures, it has created problems when thick elastomeric bearing pads have been used on structures with long spans'.

\section{Looking outside the US}

Engineers in Europe made only very limited use of rocker bearings as addressed in this paper. For tall and slender segmented rocker shoes, the danger of toppling over was omnipresent. In particular, single-segmented rocker shoes were very rarely used. For multiple-segmented rockers shoes, engineers developed topple-proof designs (e.g. Herzka, 1910). However, full-circumference rollers remained the engineers' first choice.

A similar fate was suffered by bearings with pinned or pintle rockers (Figures 2(b) and 2(c)). Pinned rocker shoes were 


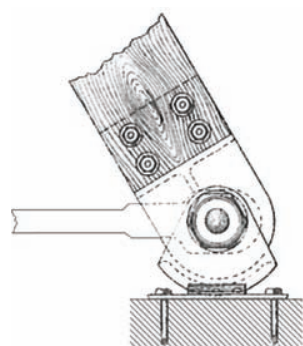

(a)

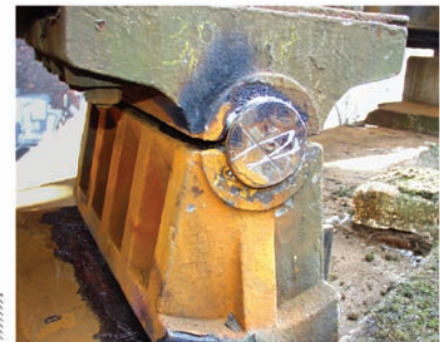

(b)

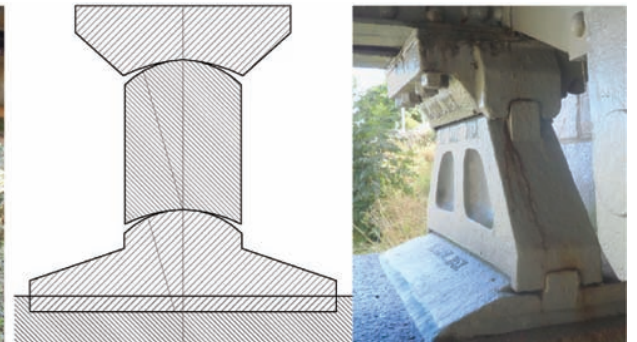

(c) (d)
Figure 8. (a) Bearing of American Bridge Co. (Schäffer and Sonne, 1882); (b) rocker bearing of Wasserturm Bridge, Berlin Ostkreuz (photo by Wetzk, coauthor); (c) rocker bearing by Haberkalt
(1920), cross-section; (d) application at Salzach Bridge (photograph reprinted with permission of Staatliches Bauamt Traunstein) discussed in 1882 with reference to the use of American pinned truss bridges (Figure 8(a)). Pintle rocker shoes were recommended in 1886 for small-span bridges (Schmid, 1886). According to Schmid, the shoes' diameter is to be chosen such that only the middle third of the shoe is necessary to cover the maximum thermal expansion or contraction of the superstructure and the outer thirds are safety precautions to prevent toppling. Even if the pintle rockers were recommended in early twentieth century for medium-length bridges (Schaper, 1908: p. 363), they were not applied in any noticeable degree. Figures 6(a) and 8(b) show rare examples in Germany.

An interesting discussion with regard to bearings as addressed in this paper can be found in the references as summarized in Haberkalt (1920). Haberkalt analysed the disadvantages of bearing types such as the danger of debris accumulation and introduced an unusual segmented rocker shoe as shown in Figure 8(c). According to Haberkalt, the choice of suitable radii at top and bottom is to influence the contact pressure and to avoid raising and lowering of the superstructure during dilatation. His publication was followed by a written disagreement with Mandl, who emphasised the danger of sliding once the shoe tilts beyond a certain degree measured with respect to the vertical. It seems that only the Salzach Bridge in Laufen-Oberndorf, connecting Germany and Austria and opened in 1903, was equipped with a bearing of this type; the bridge is still in use (Figure 8(d)).

\section{Concluding remarks}

Bridge rocker bearings may have been designed with the best of intentions and have been widely used in US bridge construction. Some of them have exhibited unacceptable behaviour. The performance of tall and slender rocker bearings used in long-span bridges has led to dangerous situations or even serious accidents. In retrospect, frequent warnings with regard to the non-redundant nature of the rockers remained unheeded.

From today's perspective, bridge rocker bearings in use are part of our engineering heritage - tens of thousands of them are still in use today and performing as anticipated. However, some lessons must be learned from the use of rocker bearings, particularly with reference to the machine-like nature of movable bearings in general: they require both a rigid substructure to function as expected and frequent maintenance with at least careful cleaning. Without these, the loss of serviceability may lead to critical levels of safety within the substructure and superstructure.

If any bearings possess 'critical deficiencies', then such an evaluation must trigger immediate action. Simply exchanging them with new bearing types sounds easy, but would finally end up in a major, costly construction project. In many cases, adjusting and cleaning the bearing with subsequent frequent maintenance will be enough to keep the rockers functioning. In cases with structural incompatibilities between rocker bearings and a non-rigid substructure, the structural integrity of the bridge might be in danger and other measures might be required.

\section{REFERENCES}

Anon (1952) Bridge collapse traced to rockers. Engineering-News Record, June 19, pp. 28-29.

Boynton RM (1952) Was viaduct support stable? Engineering News-Record, August 7, pp. 10, 16.

Caltrans (California Department of Transportation) (1994) Bridge Bearings. Memo to Bridge Designers 7-1. Caltrans, Sacramento, CA, USA, pp. 1-2, June, supersedes memo 7-1, dated 1989.

Christian GA (2010) Bridge Failures - Lessons Learned: Recent NYSDOT Bridge Failure Investigations. NYSDOT, Albany, NY, USA, seminar given at the Multidisciplinary Center for Earthquake Engineering Research, University at Buffalo, Buffalo, NY, USA, 29 March.

Cohen JM (2013) A U.S. phenomenon: tall, slender bridge rocker bearings. Stahlbau 82(12): 931-933.

Cooper T (1889) American railroad bridges. Transactions American Society of Civil Engineers 21(July): 1-52, plates $1-26$.

FHWA (Federal Highway Administration) (2006) Seismic Retrofitting Manual for Highway Structures: Part 1 - Bridges. FHWA, US Department of Transportation, Washington, DC, USA, Publication No. FHWA-HRT-06-032, p. 115, January. 
FHWA (2012) Steel Bridge Design Handbook: Bearing Design. FHWA, US Department of Transportation, Washington, DC, USA, Publication No. FHWA-IF-12-052, vol. 15, p. 6.

FHWA (2015) Steel Bridge Design Handbook: Bearing Design. FHWA, US Department of Transportation, Washington, DC, USA, Publication No. FHWA-HIF-16-002, vol. 15, pp. 4, 6, 8, December.

Haberkalt K (1920) Eine neue bewegliche Lagerung von Tragwerken. Österreichische Wochenschrift für den öffentlichen Baudienst 8(21): 385-391, plate 40 (in German); reaction Mandl, Julius at 8(29): 571-573; reaction Haberkalt at 8(29): 573-575; reaction Mandl at 8: 744-745; reaction Haberkalt at 8: 745-746.

Herzka L (1910) Ein kippsicheres Stelzenlager. Eisenbau 1(7): 280-281, 486 (in German).

KansasDOT (Kansas Department of Transportation) (2013) Roller, rocker, and pedestal bearings. Expansion Joints and Bridge Bearings. KansasDOT, Topeka, KS, USA, vol. III, April, US (LRFD), Bridge Section.

Mazroi A, Wang LRL and Murray TM (1982) Common types of bridge bearings. In Effective Coefficient of Friction of Bridge Bearings. School of Civil Engineering and Environmental Science, University of Oklahoma, Norman, OK, USA, Final Report, pp. 3-14, February.

Morison GS (1893) Expansion bearings for bridge superstructures. The Engineering Record 29(2): 21-24.

NCHRP (National Cooperative Highway Research Program) (1977) Bridge bearings. Synthesis of Highway Practice 41. NCHRP, Transportation Research Board, Washington, DC, USA. NYSDOT (New York State Department of Transportation) (2005a) New Inspection and Monitoring Requirements for High Rocker Bearings. Bridge Inspection Unit, Structures Division, NYSDOT, Albany, NY, USA, Technical Advisory, 4 October.
NYSDOT (2005b) Structural Forensic Investigation ReportPartial Failure of Ramp AC, Dunn Memorial Bridge Interchange, BIN 109299A, City of Albany, Albany County, New York, 27 July. NYSDOT, Albany, NY, USA, 20 October.

NYSDOT (2006a) Bolsters. In Bridge Manual, 4th edn, 1st US customary edn. NYSDOT, Albany, NY, USA, pp. 8-27-8-29.

NYSDOT (2006b) Bridge bearings. In Bridge Manual, 4th edn.. 1 st US customary edn. NYSDOT, Albany, NY, USA, p. 12-1, April.

NYSDOT (2014a) Inspection Manual. NYSDOT, Albany, NY, USA.

NYSDOT (2014b) Bridge Manual, 4th edn. NYSDOT, Albany, NY, USA.

PennDOT (Pennsylvania Department of Transportation) (2008) Bridge Inspection Refresher Course - Instructor Guide. PennDOT, Harrisburg, PA, USA, Session 1 on Bridge Management System, Topic 2 on Inspection \& Evaluation of Rocker Bearings, Bridge Safety Inspection Training and Certification Program, Bureau of Design, Bridge Quality Assurance Division, PennDOT, 8 October.

PennDOT (2010) Bridge Safety Inspection Manual, 2nd edn. PennDOT Harrisburg, PA, USA, Publication 238, March.

PennDOT (2014) History of Penn DOT. PennDOT, Harrisburg, PA, USA.

Schäffer T and Sonne E (eds) (1882) Handbuch der Ingenieurwissenschaften - 2. Bd: Der Brückenbau. Verlag Wilhelm Engelmann, Leipzig, Germany (in German).

Schaper G (1908) Eiserne Brücken. Ernst \& Sohn, Berlin, Germany (in German).

Schmid HD (1886) Segment-Kipplager für kleine Brücken. Wochenschrift des österreichischen Ingenieur- und Architekten-Vereines 11(34): 288 (in German).

Young TP (1952) Controversial rocker. Engineering News-Record, July 24, p. 10.

\section{WHAT DO YOU THINK?}

To discuss this paper, please submit up to 500 words to the editor at journals@ice.org.uk. Your contribution will be forwarded to the author(s) for a reply and, if considered appropriate by the editorial panel, will be published as a discussion in a future issue of the journal.

Proceedings journals rely entirely on contributions sent in by civil engineering professionals, academics and students. Papers should be 2000-5000 words long (briefing papers should be 1000-2000 words long), with adequate illustrations and references. You can submit your paper online via www.icevirtuallibrary.com/content/journals, where you will also find detailed author guidelines. 